Original article

\title{
Effect of cognitive and exercise rehabilitation on gait in male schizophrenic patients suffering from depression disorder
}

\author{
Razieh Khanmohammadi ${ }^{1}$, Mahmoud Sheikh ${ }^{1}$, Fazlolah Bagherzadeh ${ }^{1}$, Davood Hoomanian ${ }^{1}$, Daryoush Khajavi ${ }^{2}$, \\ Ina Shaw ${ }^{3}$ \\ ${ }^{1}$ University of Tehran, Tehran, Iran \\ ${ }^{2}$ Arak University, Arak, Iran \\ ${ }^{3}$ University of Zululand, KwaDlangezwa, South Africa
}

Received 27 June 2020, Revised 6 November 2020, Accepted 9 November 2020

(C) 2020, Khanmohammadi R., Sheikh M., Bagherzadeh F., Hoomanian D., Khajavi D., Shaw I.

(C) 2020, Russian Open Medical Journal

Abstract: Objective - The purpose of this study was to investigate the effect of cognitive and exercise rehabilitation training, and noninvasive brain stimulation on the gait of schizophrenic patients suffering from depression disorder.

Methods - Fifty-five male schizophrenic patients suffering from depression disorder aged 24 to 66 years were assigned to either a control group $(n=10)$, cognitive rehabilitation group $(n=10)$, exercise rehabilitation training group $(n=13)$, transcranial direct current stimulation (tDCS) group $(n=11)$ or multimodal intervention group $(n=11)$. Gait was measured using a 10-meter gait speed test under normal, in dualtask cognitive-gait, and in dual task motor-gait conditions.

Results - Gait speed during the 10-meter walk test under normal conditions was significantly $(P \leq 0.05)$ different from pre- to post-test in the exercise rehabilitation training, and cognitive rehabilitation multimodal intervention. Gait speed during the dual task motor-gait condition was significantly different from pre- to post-test in the exercise rehabilitation training, cognitive rehabilitation and, multimodal intervention groups $(P \leq 0.05)$. Gait speed during the dual task cognitive-gait condition significantly changed from pre- to post-test following exercise rehabilitation training, cognitive rehabilitation, $\mathrm{tDCS}$ and the multimodal intervention group $(P \leq 0.05)$.

Conclusion - This study's findings demonstrate that exercise rehabilitation training, cognitive rehabilitation, and multimodal interventions could assist with preventing falls within Schizophrenic patients suffering from depression and thereby improve their functional independence.

Keywords: Schizophrenic patients, gait, dual task, cognitive-gait, motor-gait.

Cite as Khanmohammadi R, Sheikh M, Bagherzadeh F, Hoomanian D, Khajavi D, Shaw I. Effect of cognitive and exercise rehabilitation on gait in male schizophrenic patients suffering from depression disorder. Russian Open Medical Journal 2020; 9: e0409.

Correspondence to Mahmoud Sheikh. Phone +982188021527. E-mail: rahmitawirza@yahoo.com.

\section{Introduction}

A high prevalence of neurological symptoms and impaired psychomotor function have been confirmed in clinical studies in patients suffering from schizophrenia [1], with depression being one of the common problems. Depressed patients have also shown a reduction in gait speed and shorter stride length [2], which predisposes them to falling and as such hospitalization [3]. Most of these patients have diminished executive functions (EFs), especially divided attention, which can result in gait disorders. Neurological patients have difficulties in performing a second task, and the dual tasking cost is higher in comparison with individuals who are healthy [4]. A reduction in the connection between the thalamus and prefrontal cortex has been shown when schizophrenic patients perform tasks. Gait during dual-task conditions may be a significant clinical indicator of a cognitive decline and a risk of falling [5]. Improving the gait while performing a task can greatly enhance the quality of life of a schizophrenic patient with impaired cognitive and motor development and reduce their risk of falling.

Walking requires attention and $E F$ in order to maintain awareness, recognition, to respond to visual demands, to prevent interference, and to allocate cognitive and motor resources while navigating through one's environment [6]. Due to brain flexibility, interventions have targeted training in cognitive areas that are associated with motor control. Research has shown that exercise can improve cognitive outcomes and physical outcomes $[7,8]$. More so, exercise rehabilitation training has been shown to effectively improve EFs $[7,9]$ and increase frontal and parietal cortical activity. However, limited research has been undertaken to investigate the impact of the exercise rehabilitation exercise on the gait.

Transcranial direct current stimulation (tDCS) is a non-invasive brain stimulation technique that is widely used in clinical and neuroscience research. It has been repeatedly shown that tDCS increases the motor function in healthy people, the elderly, 
patients with strokes, and Parkinson's patients $[10,11]$. However, the effect of tDCS on gait remains unknown.

Cognitive training has been found to improve cognitive function and has an advantageous carryover effect to some facets of mobility. However, further research is required to determine the underlying mechanisms. Further, the multimodal combination of cognitive and motor training can be superior in comparison with uni-dimensional training in some instances. The goal of this study was to investigate the effect of computer-based cognitive rehabilitation, exercise rehabilitation training, and non-invasive brain stimulation on the gait of schizophrenic patients suffering from depression disorder.

\section{Material and Methods}

\section{Patients}

In order to test this novel research hypothesis, a small number of participants were utilized in this small scale proof-of-concept investigation pretest-posttest design with three experimental groups and one control group using an intention-to-treat (ITT) analysis. This was to determine if an association does indeed exist between the various interventions and depression in schizophrenic patients.

Fifty-five male schizophrenic patients suffering from depression disorder, aged 24 to 66 years were assigned to either a control group, cognitive rehabilitation group, exercise rehabilitation training group, transcranial direct current stimulation (tDCS) group or multimodal intervention group.

All patients had to meet the following inclusion criteria: ability to understand and speak, score 11 or higher in the Beck Depression Inventory Short Version (BDI-S), had no cardiovascular, neuromuscular, and endocrine disease or physical disorders, did not regularly participate in exercise, no alcohol addiction in the past three months, no drug addiction, no history of head injury and previous seizure, no severe symptoms of schizophrenia, and no history of mental retardation or senile dementia and hospitalized for more than one year in psychiatric wards.

After acquiring ethical approval from the institutional review board of University of Tehran in Iran, registering the clinical trial (IRCT20190908044722N1), obtaining permission from the rehabilitation facility and informed consent from the patients or guardian, the trial was carried out under the supervision of a registered psychiatrist, two registered clinical psychologists, two nurses and a sports coach. This study was performed in accordance with the ethical standards as laid down in the 1964 Declaration of Helsinki and its later amendments.

\section{Instruments and procedures}

The Beck Depression Inventory Short Version (BDI-S) was administered by the psychiatrist. Out of the 70 patients hospitalized at the clinic, 55 patients scored higher than 11 and was diagnosed with major depression disorder. The cognitive state of each patient was assessed using the mini-mental state examination (MMSE) by a clinical psychologist. After these examinations, the patients were homogeneously assigned to a one of the following groups; control, cognitive rehabilitation, exercise rehabilitation training, transcranial direct current stimulation (tDCS) or multimodal intervention, based on their age, depression score, and MMSE score. The patients in the intervention groups participated in their respective programs for 12 weeks while the control group continued their normal activities without any intervention. Antipsychotic medication was kept stable for two weeks before inclusion in the study and during the study period.

The Beck Depression Inventory Short Version (BDI-S) of Dadfar and Kalibatseva (2016) contained 13 self-report items that expresses specific symptoms of depression. Each item of this questionnaire included a four-point Likert-scale that ranged from 0 to 3 . The maximum score and minimum score are 39 and zero, respectively. A reliability of 0.85 has previously been reported [12].

The Mini Mental State Examination (MMSE) consisted of 14 questions that examined the cognitive abilities of the patients. The maximum score on this examination is 30 and a score below 25 suggested the possible decline in cognition and a score below 20 indicated a definite decline [13].

The 10-metre walk test is a performance measure that was used to assess gait speed in meters per second. This test was completed twice, and the average was used in the final analysis [14]. The patients completed a 10-meter walk test while engaging in a one-back secondary spatial visual task. Patients were asked to look at a projected image that was placed on the opposite end, one meter away from the finish line. A number of visual stimuli appeared consecutively on the screen. Patients were required to indicate whether the image was "similar" - if there was a similarity between the projected image and the preceding one - otherwise indicate "dissimilar" if the projected image and preceding one was not alike. This was completed twice, and the average time was used in the final analysis. The patients were required to complete a 10-meter walk test while carrying a cup filled with water with their dominant hand. If any water was spilled, the test was considered a failure. The test was completed twice, and the average time was used in the final analysis.

\section{Intervention}

The exercise rehabilitation training group participated in a $12-$ week exercise rehabilitation training program, three times a week for 60 minutes. Each session commenced with a 10-minute warmup consisting of general calisthenics. This was followed by 45 minutes of treadmill walking and cycling at $60 \%$ heart rate maximum (HRmax) in week one, 65\% HRmax in week two, 70\% HRmax in week three and 75\% HRmax used in weeks four to 12 and a five-minute cool down [15].

The cognitive rehabilitation group participated in Attentive Rehabilitation of Attention and Memory (ARAM) sessions for 45 to 60 minutes, three times a week for 12 weeks. The ARAM program was designed to improve different dimensions of attention and memory (selective, sustained, shifting, and divided). This package was designed based on the attention model of the Sohlberg and Mateer and active working memory model of Baddeley, and progressive smart exercises were developed based on these models. Tasks included colored-homes task, faces task, similar windows task, marked tables task, segmented images task, acronym making task, last colors task, animal tracking task, repetitive images task, letter matching task, and delay color matching task. All tasks had 10 difficulty levels based on the number of stimulants, speed of presentation, and their complexity and rules.

The tDCS group underwent brain stimulation using the Neurostism2 ${ }^{\mathrm{TM}}$ (Medinateb, Iran) two-channel electrical brain stimulation device. Once a week, the anode electrode $\left(16 \mathrm{~cm}^{2}\right)$ was placed on M1 of the motor and premotor areas (area $10-20 \%$ of $\mathrm{Cz}$ 
point in both hemispheres based on the 10-20 system). The cathode electrode $\left(24 \mathrm{~cm}^{2}\right)$ was placed in the center of the forehead to prevent the direct lateral current. The right hemisphere was stimulated in the morning and the left hemisphere in the afternoon. Also, twice weekly, the anode electrode $\left(16 \mathrm{~cm}^{2}\right)$ was placed on the dorsa lateral prefrontal (F3 point based on the 10-20 system), and the cathode electrode $\left(24 \mathrm{~cm}^{2}\right)$ was placed on the contralateral deltoid muscle. The large size of the cathode electrode made it ineffective in terms of performance without affecting the anode electrode.

The multimodal intervention consisted of exercise rehabilitation training, cognitive rehabilitation, and tDCS. The multimodal intervention group participated in ARAM cognitive rehabilitation sessions three times a week for 10 minutes. This group also completed eight weeks, twice weekly exercise rehabilitation training for 60 minutes using a similar protocol to the exercise rehabilitation training group. From weeks nine to 12 , this group underwent brain stimulation. Three times a week on even days, the anode electrode $\left(16 \mathrm{~cm}^{2}\right)$ was placed on $\mathrm{M} 1$ of the motor and premotor areas (area $10-20 \%$ of $\mathrm{Cz}$ point in both hemispheres based on the 10-20 system). The cathode electrode $\left(24 \mathrm{~cm}^{2}\right)$ was placed in the center of the forehead to prevent the direct lateral current. The right hemisphere was stimulated in the morning and the left hemisphere in the afternoon. Also, three times a week on odd days, the anode electrode $\left(16 \mathrm{~cm}^{2}\right)$ was placed on the dorsa lateral prefrontal (F3 point based on the 10-20 system), and the cathode electrode $\left(24 \mathrm{~cm}^{2}\right)$ was placed on the contralateral deltoid muscle.

\section{Data analysis}

The data were analyzed with the statistical analysis program Statistical Package for Social Sciences (SPSS) version 20 for Windows (SPSS Inc., Chicago, IL, USA) which calculated the descriptive statistics including the means and standard deviations of the data collected. Inferential statistics such as KolmogorovSmirnov test were used to determine normality of data distribution. One-way ANOVA was used for analyses of demographic characteristics of the intervention and control groups and RM-ANOVA was used for within and between groups comparisons. P-values were considered significant at equal or less than 0.05 .

\section{Results}

The groups had no significant difference with regard to their age, depression score, and MMSE score at pre-test $(P \geq 0.05)$ (Table 1). Gait speed during the 10-meter walk test under normal conditions was significantly $(P \leq 0.05)$ different from pre- to posttest in the exercise rehabilitation training, and cognitive rehabilitation multimodal intervention, but not in the tDCS and control groups. The results further demonstrated that there was a significant difference between the exercise rehabilitation training, cognitive rehabilitation, tDCS, multimodal intervention and control groups in terms of gait speed under normal conditions $(P=0.024)$ (Table 2).

Gait speed during the dual task motor-gait condition was significantly different from pre- to post-test in the exercise rehabilitation training, cognitive rehabilitation and, multimodal intervention groups $(P \leq 0.05)$. However, no significant differences were found in gait speed during dual task motor-gait condition from pre- to post-test in the tDCS and control groups $(P \geq 0.05)$. Further, there was a significant difference between the exercise rehabilitation training, cognitive rehabilitation, tDCS, multimodal intervention and control groups in terms of gait speed during the dual task motor-gait condition ( $P=0.026)$ (Table 2).

Gait speed during the dual task cognitive-gait condition significantly changed from pre- to post-test following exercise rehabilitation training, cognitive rehabilitation, tDCS and the multimodal intervention group ( $P \leq 0.05)$, but remained unchanged in the control group $(P \geq 0.05)$. In addition, gait speed during the dual task cognitive-gait condition was found to be significantly different between the exercise rehabilitation training, cognitive rehabilitation, tDCS, multimodal intervention and control groups $(P=0.038)$ (Table 2).

Table 1: Analyses of demographic characteristics of the intervention and control groups using One-way ANOVA (N=55)

\begin{tabular}{|c|c|c|c|c|c|c|}
\hline & $\begin{array}{c}\text { Exercise Rehabilitation } \\
\text { Group }(n=13)\end{array}$ & $\begin{array}{c}\text { Cognitive Rehabilitation } \\
\text { Group }(n=10)\end{array}$ & $\begin{array}{c}t D C S \\
\text { Group }(n=11)\end{array}$ & $\begin{array}{c}\text { Multimodal Intervention } \\
\text { Group }(n=11)\end{array}$ & $\begin{array}{c}\text { Control } \\
\text { Group }(n=10)\end{array}$ & $\begin{array}{c}\text { Between } \\
\text { group P-value }\end{array}$ \\
\hline Age, years & $46.4 \pm 10.4$ & $47.5 \pm 8.4$ & $48.0 \pm 11.9$ & $43.4 \pm 12.7$ & $47.0 \pm 14.5$ & 0.900 \\
\hline Depression Score & $18.3 \pm 5.1$ & $16.7 \pm 3.4$ & $19.9 \pm 6.2$ & $18.7 \pm 7.8$ & $23.1 \pm 7.1$ & 0.190 \\
\hline MMSE Score & $23.9 \pm 3.3$ & $23.1 \pm 4.5$ & $23.5 \pm 4.5$ & $24.1 \pm 2.5$ & $21.6 \pm 6.1$ & 0.670 \\
\hline
\end{tabular}

Data presented as means \pm standard deviation. tDCS, transcranial direct current stimulation (tdcs); MMSE, mini-mental state examination.

Table 2: Results of RM-ANOVA for within groups comparisons

\begin{tabular}{|c|c|c|c|c|c|c|c|c|c|}
\hline \multirow[t]{2}{*}{ Group } & \multicolumn{2}{|c|}{$\begin{array}{l}\text { Gait Speed under Normal } \\
\text { Conditions }\end{array}$} & \multirow{2}{*}{$\begin{array}{c}\text { Within groups } \\
\text { comparison } \\
\text { (P-value) }\end{array}$} & \multicolumn{2}{|c|}{$\begin{array}{l}\text { Gait Speed in Dual Task } \\
\text { Motor-Gait Conditions }\end{array}$} & \multirow{2}{*}{$\begin{array}{c}\text { Within groups } \\
\text { comparison } \\
\text { (P-value) }\end{array}$} & \multicolumn{2}{|c|}{$\begin{array}{l}\text { Gait Speed in Dual Task } \\
\text { Cognitive-Gait Conditions }\end{array}$} & \multirow{2}{*}{$\begin{array}{c}\text { Within groups } \\
\text { comparison } \\
\text { (P-value) }\end{array}$} \\
\hline & Pre-test & Post-test & & Pre-test & Post-test & & Pre-test & Post-test & \\
\hline $\begin{array}{l}\text { Exercise } \\
\text { rehabilitation group }\end{array}$ & $10.5 \pm 3.8$ & $8.4 \pm 2.5^{*}$ & 0.021 & $12.6 \pm 5.4$ & $8.5 \pm 2.6^{*}$ & 0.001 & $25.6 \pm 8.7$ & $18.7 \pm 5.8^{*}$ & 0.001 \\
\hline $\begin{array}{l}\text { Cognitive } \\
\text { rehabilitation group }\end{array}$ & $8.8 \pm 1.6$ & $7.8 \pm 1.6^{*}$ & 0.041 & $10.7 \pm 2.6$ & $9.0 \pm 2.8^{*}$ & 0.022 & $19.5 \pm 6.8$ & $15.7 \pm 7.1^{*}$ & 0.021 \\
\hline tDCS Group & $11.0 \pm 2.7$ & $10.3 \pm 3.5$ & 0.061 & $13.7 \pm 4.9$ & $11.9 \pm 3.5$ & 0.081 & $34.5 \pm 17.4$ & $29.2 \pm 16.2^{*}$ & 0.001 \\
\hline $\begin{array}{l}\text { Multimodal } \\
\text { intervention group }\end{array}$ & $10.7 \pm 2.2$ & $8.3 \pm 1.5^{*}$ & 0.024 & $12.6 \pm 3.4$ & $8.9 \pm 2.4^{*}$ & 0.001 & $25.4 \pm 11.8$ & $16.5 \pm 7.6^{*}$ & 0.001 \\
\hline Control group & $10.3 \pm 2.6$ & $10.6 \pm 2.6^{*}$ & 0.141 & $11.1 \pm 3.2$ & $11.6 \pm 2.5$ & 0.213 & $32.8 \pm 19.0$ & $32.7 \pm 18.5$ & 0.091 \\
\hline
\end{tabular}

Data presented as means \pm standard deviation. * significant difference from pre- to post-test $(p \leq 0.05)$.

tDCS, transcranial direct current stimulation. 


\section{Discussion}

This study found that exercise rehabilitation training, cognitive rehabilitation, and the multimodal interventions improved the patients' gait speed under normal, dual task cognitive-gait, and dual task motor-gait conditions, while the tDCS group's gait speed improved under dual task cognitive-gait conditions. Exercise rehabilitation training might have been effective in improving gait speed, since repetitive training as used during the walking and cycling's flexion and extensions movements patterns fosters motor learning because it enables the system to coordinate muscles [16]. Cycling's bilateral movement of the lower limbs requires muscle coordination, effectively increasing the ability to walk. Also, cycling can improve gait speed by stimulating the motor area in the central nervous system and activating the cerebral cortex. Further, this study found improvements in gait speed under both dual task conditions. This was likely as a result of the exercise rehabilitation training requiring cognitive processes [17]. Higher-order cognitive functions such as EFs and attention are utilized during walking [18]. Executive function plays an important role in the ability to walk and to perform another task simultaneously [19]. Since several studies have shown the effectiveness of exercise rehabilitation training on the cognitive function in patients suffering from schizophrenia $[20,21]$, the improvement in gait speed under dual task conditions following exercise rehabilitation training can be attributed to the improvement of the patients' EFs.

This study demonstrated the effectiveness of cognitive rehabilitation in improving gait speed under normal and both dual task conditions. Patients suffering from gait disorders could have an atrophied frontal lobe, which is problematic since it contributes towards EFs [22]. The findings of the present study are in line with previous studies that have shown the benefits of cognitive rehabilitation on pre-frontal activity patterns and non-trained cognitive domains or distal functions like mobility $[23,24]$. Cognitive rehabilitation with an intense emphasis on executive control practice likely has a beneficial effect on gait and EFs through its impact on the frontosubcortical circuit [25]. The frontosubcortical circuit connects special areas of the frontal cortex (i.e., pre-frontal cortex) to the basal ganglia (motor control) [26]. As such, due to its flexibility, the brain is able to constantly change its response to cognitive, sensory or motor activities. Optimization of gait performance is associated with less risk of falling, especially under dual task conditions following cognitive rehabilitation [27]. Therefore, cognitive rehabilitation could be a promising approach to prevent falling, especially in participants who are unwilling to perform physical activity interventions [28].

The tDCS intervention of the present study did not improve gait speed under normal and dual task motor-gait conditions. Many motor learning paradigms include relatively simple movements of the upper limb [29], while walking requires complex movements of joints and the coordination of various sensory and motor systems [30]. Also, the lack of improvement in gait speed following the tDCS intervention might be due this study not stimulating the pre-motor area in two hemispheres simultaneously. Previous studies stimulated the cerebellum which might be more effective at improving gait since the cerebellum controls essential and multiple gait dimensions [31]. This study further demonstrated an improvement in gait speed under the dual task cognitive-gait condition. This was likely as a result of the tDCS anodal stimulation on the left dorsolateral prefrontal cortex. As such, cognitive but not motor improvement by stimulation improves gait speed. This could be attributed to the patients' capacity for recruiting and allocating available cognitive resources.

The results of this study showed that cognitive rehabilitation was superior to tDCS in improving gait speed under normal conditions. Further, this study found that exercise rehabilitation training, cognitive rehabilitation, and multimodal interventions were superior compared to tDCS in improving gait speed under both dual task conditions. In order to combine each protocol within the multimodal intervention, this study reduced some elements of the exercise rehabilitation training, cognitive rehabilitation, and tDCS protocols to accommodate for duration. Wollesen and Voelcker-Rehage (2013) showed that not only does the type of exercise, but also the level of exercise affects dual task outcomes [32]. Therefore, the multimodal intervention may not have produced sufficient stimulus to induce the requisite changes. It must be noted that since this study utilized a small scale proofof-concept investigation design to determine if an association does indeed exist between the interventions and depression in schizophrenic patients, larger confirmatory studies are required to confirm this association or lack thereof as in the multimodal intervention.

\section{Conclusion}

Many schizophrenic patients suffer from neurological symptoms and impaired psychomotor function, with depression being one of the common problems. Depressed patients frequently have a reduced gait speed predisposing them to falling. This study's findings demonstrate that exercise rehabilitation training, cognitive rehabilitation, and multimodal interventions could assist with preventing falls within this population and thereby improve their functional independence.

\section{Conflict of interest}

No potential conflict of interest was reported by the authors.

\section{Ethical approval}

All procedures performed in studies involving human participants were in accordance with the ethical standards of the institutional and/or national research committee and with the 1964 Declaration of Helsinki and its later amendments or comparable ethical standards.

\section{Funding}

There was no funding for this research.

\section{References}

1. Koo PC, Berger C, Kronenberg G, Bartz J, Wybitul P, Reis O, et al. Combined cognitive, psychomotor and electrophysiological biomarkers in major depressive disorder. Eur Arch Psychiatry Clin Neurosci 2019; 269(7): 823-832. https://doi.org/10.1007/s00406-018-0952-9.

2. Lemke MR, Wendorff $T$, Mieth $B$, Buhl K, Linnemann $M$. Spatiotemporal gait patterns during over ground locomotion in major depression compared with healthy controls. J Psychiatr Res 2000; 34(4-5): 277-283. https://doi.org/10.1016/s0022-3956(00)00017-0.

3. Montero-Odasso $M$, Schapira $M$, Soriano $E R$, Varela $M$, Kaplan $R$, Camera LA, et al. Gait velocity as a single predictor of adverse events in healthy seniors aged 75 years and older. J Gerontol A Biol Sci Med Sci 2005; 60(10): 1304-1309. https://doi.org/10.1093/gerona/60.10.1304.

4. Hakakzadeh A, Shariat A, Honarpishe R, Moradi V, Ghannadi S, Sangelaji B, et al. Concurrent impact of bilateral multiple joint functional electrical stimulation and treadmill walking on gait and 
spasticity in post-stroke survivors: a pilot study. Physiother Theory Pract 2019; 1-9. https://doi.org/10.1080/09593985.2019.1685035.

5. Kargarfard M, Shariat A, Ingle L, Cleland JA, Kargarfard M. Randomized Controlled Trial to Examine the Impact of Aquatic Exercise Training on Functional Capacity, Balance, and Perceptions of Fatigue in Female Patients With Multiple Sclerosis. Arch Phys Med Rehabil 2018; 99(2); 234-241. https://doi.org/10.1016/i.apmr.2017.06.015.

6. Baker J, Castro A, Dunn AK, Mitra S. Asymmetric interference between cognitive task components and concurrent sensorimotor coordination. J Neurophysiol 2018; 120(7): 330-342. https://doi.org/10.1152/jn.00073.2018.

7. Firth J, Stubbs B, Rosenbaum S, Vancampfort D, Malchow B, Schuch F, et al. Aerobic exercise improves cognitive functioning in people with schizophrenia: a systematic review and meta-analysis. Schizophr Bull 2017; 43(3): 546-556. https://doi.org/10.1093/schbul/sbw115.

8. Campos C, BF Rocha N, Lattari E, E Nardi A, Machado S. Exercise induced neuroplasticity to enhance therapeutic outcomes of cognitive remediation in schizophrenia: analyzing the Role of Brai Nderived Neurotrophic Factor. CNS Neurol Disord Drug Targets 2017; 16(6): 638651. https://doi.org/10.2174/1871527315666161223142918.

9. Hosseini L, Shariat A, Ghaffari MS, Honarpishe R, Cleland JA. The effect of exercise therapy, dry needling, and nonfunctional electrical stimulation on radicular pain: a case report. J Exerc Rehabil 2018; 14(5): 864-869. https://doi.org/10.12965/jer.1836356.178.

10. Ghayour-Najafabadi M, Memari AH, Hosseini L, Shariat A, Cleland JA. Repetitive Transcranial Magnetic Stimulation for the Treatment of Lower Limb Dysfunction in Patients Poststroke: A Systematic Review with Meta-Analysis. J Stroke Cerebrovasc Dis 2019; 28(12): 104412. https://doi.org/10.1016/j.jstrokecerebrovasdis.2019.104412.

11. Koutsouleris N, Wobrock T, Guse B, Langguth B, Landgrebe $M$, Eichhammer $\mathrm{P}$, et al. Predicting response to repetitive transcranial magnetic stimulation in patients with schizophrenia using structural magnetic resonance imaging: a multisite machine learning analysis. Schizophr Bull 2018; 44(5): 1021-1034. https://doi.org/10.1093/schbul/sbx114.

12. Dadfar M, Kalibatseva Z. Psychometric properties of the persian version of the short beck depression inventory with Iranian psychiatric outpatients. Scientifica (Cairo) 2016; 2016: 8196463. https://doi.org/10.1155/2016/8196463.

13. Folstein MF, Folstein SE, McHugh PR. "Mini-mental state": a practical method for grading the cognitive state of patients for the clinician. $J$ Psychiatr Res 1975; 12(3): 189-198. https://doi.org/10.1016/00223956(75)90026-6.

14. Yoshino Y, Yoshida T, Mori T, Hirota S, Iga J, Ueno S. Risk of idiopathic normal pressure hydrocephalus in older inpatients with schizophrenia. Int Psychogeriatr 2016; 28(5): 863-868. https://doi.org/10.1017/s1041610215001763.

15. Kimhy D, Vakhrusheva J, Bartels MN, Armstrong HF, Ballon JS, Khan S, et al. The impact of aerobic exercise on brain-derived neurotrophic factor and neurocognition in individuals with schizophrenia: a singleblind, randomized clinical trial. Schizophr Bull 2015; 41(4): 859-868. https://doi.org/10.1093/schbul/sbv022.

16. Thielman GT, Dean CM, Gentile AM. Rehabilitation of reaching after stroke: task-related training versus progressive resistive exercise. Arch Phys Med Rehabil 2004; 85(10): 1613-1618. https://doi.org/10.1016/j.apmr.2004.01.028.

17. Al-Yahya E, Dawes H, Smith L, Dennis A, Howells K, Cockburn J. Cognitive motor interference while walking: a systematic review and meta-analysis. Neurosci Biobehav Rev 2011; 35(3): 715-728. https://doi.org/10.1016/j.neubiorev.2010.08.008.

18. Mirelman A, Herman T, Brozgol M, Dorfman M, Sprecher E, Schweiger $A$, et al. Executive function and falls in older adults: new findings from a five-year prospective study link fall risk to cognition. PloS One 2012; 7(6): e40297. https://doi.org/10.1371/journal.pone.0040297.
19. Brustio PR, Magistro D, Zecca M, Liubicich ME, Rabaglietti E. Fear of falling and activities of daily living function: mediation effect of dualtask ability. Aging Ment Health 2018; 22(6): 856-861. https://doi.org/10.1080/13607863.2017.1318257.

20. Kurebayashi Y, Otaki J. Association between altered physical activity and neurocognitive function among people with schizophrenia: A minimum 6-months' follow-up study. Compr Psychiatry 2017; 77: 4552. https://doi.org/10.1016/j.comppsych.2017.06.001.

21. Akbas E. The Effectiveness of Pilates Training on Physical Parameters in Patients with Schizophrenia. New Trends and Issues Proceedings on Advances in Pure and Applied Sciences 2017; (8): 123-128. http://doi.org/10.18844/gjapas.v0i8.2826.

22. Pirker W, Katzenschlager R. Gait disorders in adults and the elderly. Wien Klin Wochenschr 2017; 129(3-4): 81-95. https://doi.org/10.1007/s00508-016-1096-4.

23. Verghese J, Mahoney J, Ambrose AF, Wang C, Holtzer R. Effect of cognitive remediation on gait in sedentary seniors. J Gerontol A Biol Sci Med Sci 2010; 65(12): 1338-1343. https://doi.org/10.1093/gerona/glq127.

24. Smith-Ray RL, Makowski-Woidan B, Hughes SL. A randomized trial to measure the impact of a community-based cognitive training intervention on balance and gait in cognitively intact black older adults. Health Educ Behav 2014; 41(1_suppl): 62S-69S. https://doi.org/10.1177/1090198114537068.

25. Verghese J, Ayers E, Mahoney JR, Ambrose A, Wang C, Holtzer R. Cognitive remediation to enhance mobility in older adults: the CREM study. Neurodegener Dis Manag 2016; 6(6): 457-466. https://doi.org/10.2217/nmt-2016-0034.

26. Alexander GE, DeLong MR, Strick PL. Parallel organization of functionally segregated circuits linking basal ganglia and cortex. Annu Rev Neurosci 1986; 9(1): 357-381. https://doi.org/10.1146/annurev.ne.09.030186.002041.

27. Verghese J, Buschke H, Viola L, Katz M, Hall C, Kuslansky G, et al. Validity of divided attention tasks in predicting falls in older individuals: a preliminary study. J Am Geriatr Soc 2002; 50(9): 15721576. https://doi.org/10.1046/j.1532-5415.2002.50415.x.

28. Smith-Ray RL, Hughes SL, Prohaska TR, Little DM, Jurivich DA, Hedeker D. Impact of cognitive training on balance and gait in older adults. J Gerontol B Psychol Sci Soc Sci 2015; 70(3): 357-366. https://doi.org/10.1093/geronb/gbt097.

29. Ammann C, Spampinato D, Márquez-Ruiz J. Modulating motor learning through transcranial direct-current stimulation: an integrative view. Front Psychol 2016; 1981. https://doi.org/10.3389/fpsyg.2016.01981.

30. Bollens B, Crevecoeur F, Detrembleur C, Warlop T, Lejeune TM. Variability of human gait: effect of backward walking and dual-tasking on the presence of long-range autocorrelations. Ann Biomed Eng 2014; 42(4): 742-750. https://doi.org/10.1007/s10439-013-0961-9.

31. Thach WT, Bastian AJ. Role of the cerebellum in the control and adaptation of gait in health and disease. Prog Brain Res 2004; 143: 353-366. https://doi.org/10.1016/s0079-6123(03)43034-3.

32. Wollesen B, Voelcker-Rehage C. Training effects on motor-cognitive dual-task performance in older adults. Eur Rev Aging Phys Act 2014; 11(1): 5-24. https://doi.org/10.1007/s11556-013-0122-z.

\section{Authors:}

Razieh Khanmohammadi - PhD, Lecturer, Department of Motor Behavior, Faculty of Physical Education and Sport Science, University of Tehran, Tehran, Iran. http://orcid.org/0000-0003-4941-6085.

Mahmoud Sheikh - PhD, Associate Professor, Department of Motor Behavior, Faculty of Physical Education and Sport Science, University of Tehran, Tehran, Iran. http://orcid.org/0000-0002-5730-0165.

Fazlolah Bagherzadeh - PhD, Associate Professor, Department of Motor Behavior, Faculty of Physical Education and Sport Science, University of Tehran, Tehran, Iran. 
Davood Hoomanian - PhD, Assistant Professor, Department of Motor Behavior, Faculty of Physical Education and Sport Science, University of Tehran, Tehran, Iran. http://orcid.org/0000-00033250-832x.

Daryoush Khajavi - PhD, Associate Professor, Department of Motor Behavior, Faculty of Sport Sciences, Arak University, Arak, Iran.

Ina Shaw - PhD, Professor, Department of Human Movement Science,

University of Zululand, KwaDlangezwa, South Africa. http://orcid.org/00000001-8400-8234. 